\title{
Complete Genome Sequence Resource for Xanthomonas fragariae Causing Crown Infection Pockets in Strawberry
}

\author{
Feng Wei, ${ }^{1,2}$ Danjuan Wang, ${ }^{1,2}$ Sihao Fan,, ${ }^{1,2}$ Jiancheng Shi, ${ }^{1,2}$ Xiaolin Cai,, ${ }^{1,2}$ Yulian $\mathrm{Li}^{1,2}$ \\ Yangyang Ma, ${ }^{1,2}$ Yingqiang Wen, ${ }^{1, \dagger}$ and Jiayue Feng ${ }^{1,2, \dagger}$ \\ ${ }^{1}$ State Key Laboratory of Crop Stress Biology for Arid Areas, College of Horticulture, Northwest \\ A\&F University, Yangling 712100, Shaanxi, China \\ ${ }^{2}$ Key Laboratory of Protected Horticulture Engineering in Northwest China, Ministry of Agriculture, \\ Yangling 712100, Shaanxi, China
}

\begin{abstract}
Xanthomonas fragariae is a global quarantine pathogen, which typically inflicts angular leaf spots. In the present study, we report a new 4.11-Mb high-quality genome sequence of $X$. fragariae YL19. YL19 can cause the typical angular leaf spot symptoms on strawberry plants in China as well as crown infection pocket symptoms. This new symptom has not been reported in other $X$. fragariae. Compared with typical $X$. fragariae strains, including PD885, NBC2815, PD5205, Fap21, and Fap29, the genome and plasmid in YL19 were smaller in size, lacking 109 coding genes, and have more carbohydrate-active enzyme and secondary metabolism genes. The YL19 genome ought to clarify the molecular mechanisms of genome evolution, host adaptation, and pathological process of $X$. fragariae and help improve strawberry management strategies.
\end{abstract}

\section{Genome Announcement}

Strawberry is a perennial herb of the genus Fragaria in the family Rosaceae and is known as the "queen of berries," one of the most widely consumed fruits in the world (Amil-Ruiz et al. 2011). X. fragariae is a bacterial quarantine pathogen of strawberry and the cause of angular leaf spot, which can significantly affect the production of strawberries. It was initially described within the United States in 1962 and has since unfolded globally (Kennedy and King 1962). Under favorable conditions, the pathogen might cause vital harm to nurseries and production of strawberries (Kim et al. 2016; Roberts et al. 1997).

Recently, it was reported that the isolate of $X$. fragariae YL19 can result not only in the typical symptoms of angular leaf spot but also crown infection pocket symptoms in the infected strawberry plants (Li et al. 2021; Song et al. 2021). Since the 2017 growing season, the strawberry crown infection pocket disease caused by $X$. fragariae YL19 emerged in multiple provinces or regions in China, including Liaoning, Yunnan, Zhejiang, and Beijing (F. F. Sui, personal communication). The disease incidence is estimated to be 5 to $10 \%$ in general but could reach 30 to $40 \%$ in some strongly affected plastic tunnels (F. F. Sui, personal communication). Until now, a total of 62 genome sequences of $X$. fragariae were made publicly available (Gétaz et al. 2017; Henry and Leveau 2016; Vandroemme et al. 2013). However, no strain was reported to cause crown infection pockets affecting strawberry plants (Fig. 1). Therefore, revealing the $X$. fragariae YL19 genome sequence could increase our understanding of crown infection pocket symptoms and provides a reference for facilitating each pathogenicity mechanism study.

\footnotetext{
${ }^{\dagger}$ Corresponding authors: J. Feng; fengjy19151@ nwsuaf.edu.cn, and Y. Wen; wenyq@ nwsuaf.edu.cn
}

The author(s) declare no conflict of interest.

Accepted for publication 10 October 2021.

(c) (1) () $\odot$ Copyright ()$^{2} 222$ The Author(s). This is an open access article distributed under the CC BY-NC-ND (c) 4.0 International license.

\section{Funding}

This study was financially supported by grants from the Agriculture Sci-Tech of Xi'an (20193020YF008NS008) and the fundamental research funds for the Central universities (2452020042).

\section{Keywords}

crown infection pockets, genome, strawberry, Xanthomonas fragariae 

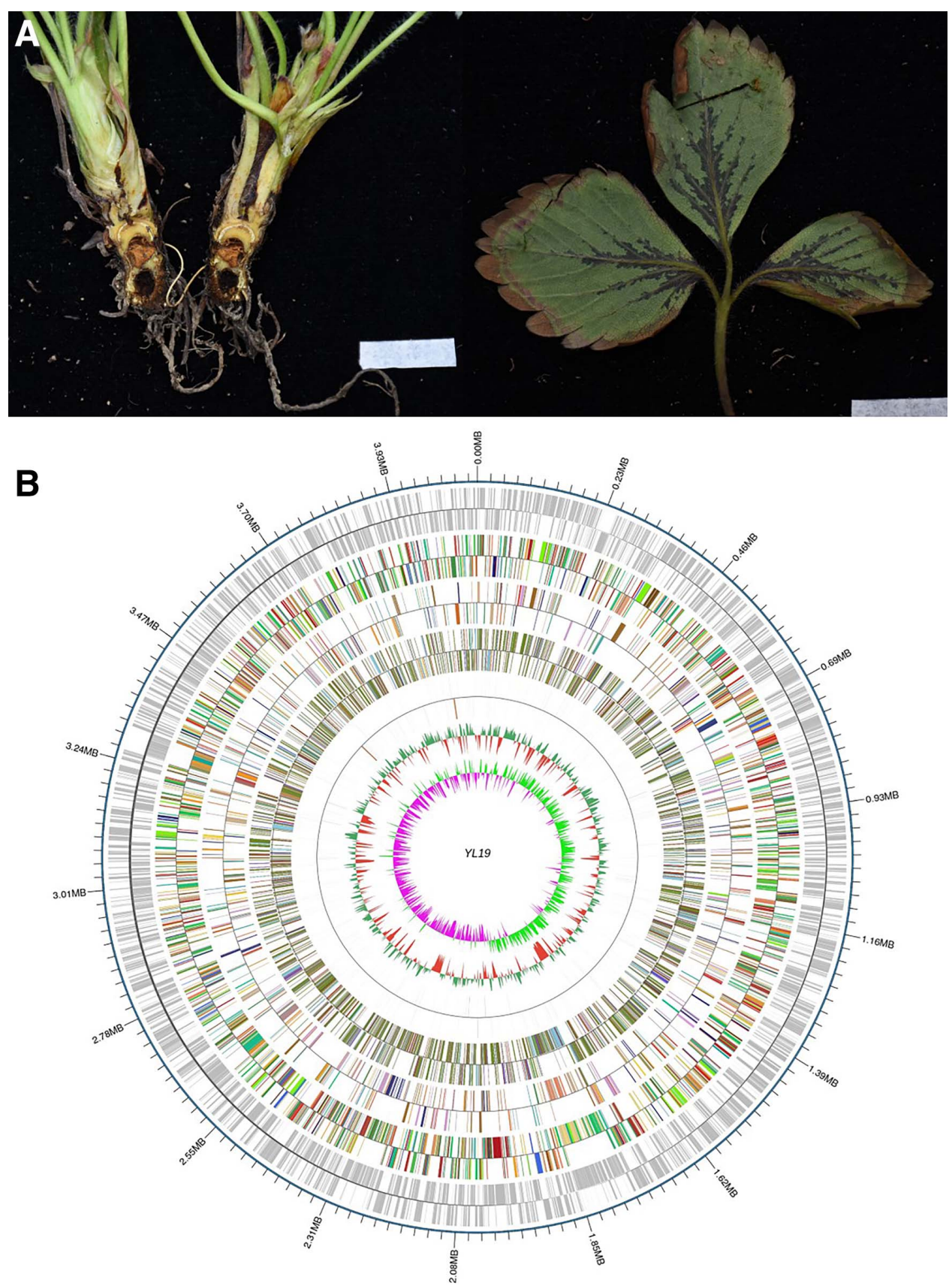

Fig. 1. The crown infection pocket symptoms and a whole-genome map of Xanthomonas fragariae YL19. A, The crown infection pocket symptoms in strawberry. B, Whole-genome map of $X$. fragariae YL19. The outer circle is the genomic sequence position coordinates. Rings from the outside to inside represent gene function annotation (Cluster of Orthologous Groups, Gene Ontology, and Kyoto Encyclopedia of Genes and Genomes), noncoding RNA, and GC content. The GC content is counted by window (chromosome length/1,000) bases, step (chromosome length/1,000) bases.

In the present study, we report the genome sequence of the $X$. fragariae YL19 strain, which was isolated from infected strawberry stems (Fragaria $\times$ ananassa Duch.) within the Liaoning province of China in 2019 (Li et al. 2021; Song et al. 2021). It was confirmed by the internal transcribed spacer region (accession number MT513132.1, MW233896, MW233897, and MW233895) and was plated on sucrose peptone agar medium at $25^{\circ} \mathrm{C}$ in constant darkness (Li et al. 2021). Genomic DNA was extracted with the sodium dodecyl sulfate method (Moslem et al. 2010). The harvested DNA was detected by the agarose gel electrophoresis and was quantified with a Qubit 2.0 fluorometer (Thermo Scientific). The whole genome of YL19 was sequenced using the Nanopore PromethION platform and Illumina NovaSeq PE150 at the Beijing Novogene Bioinformatics Technology Co., Ltd (Beijing). Libraries for 
Table 1. Comparison of YL19 with FaP21, FaP29, PD5205, PD885, and NBC2815 genomes

\begin{tabular}{|c|c|c|c|c|c|c|}
\hline \multirow[b]{2}{*}{ Parameters } & \multicolumn{6}{|c|}{ Statistics } \\
\hline & $\begin{array}{c}\text { YL19 } \\
(2020)^{a}\end{array}$ & $\begin{array}{l}\text { FaP21 } \\
\left(_{(2011)^{b}}\right.\end{array}$ & $\begin{array}{l}\text { FaP29 } \\
(2011)^{b}\end{array}$ & $\begin{array}{l}\text { PD5205 } \\
(2005)^{c}\end{array}$ & $\begin{array}{l}\text { PD885 } \\
(1960)^{c}\end{array}$ & $\begin{array}{l}\text { NBC2815 } \\
(2011)^{c}\end{array}$ \\
\hline No. bases (bp) & $6,016,963,541$ & $513,923,760$ & $513,912,240$ & $1,058,133,921$ & $1,185,992,834$ & $866,435,465$ \\
\hline Genome coverage & 1,471 & $120 x$ & $120 x$ & $247 x$ & $274 x$ & $203 x$ \\
\hline Genome size (bp) & $4,107,640$ & $4,282,698$ & $4,282,602$ & 4283943 & 4328441 & 4268155 \\
\hline No. plasmids & 1 & 2 & 2 & 2 & 2 & 1 \\
\hline Plasmid size (bp) & pYL19, 20,156 & $\begin{array}{l}\text { pFap21-1, } \\
29,232 \\
\text { pFap21-2, } \\
20,831\end{array}$ & $\begin{array}{l}\text { pFap29-1, } \\
29,138 \\
\text { pFap29-2, } \\
20,831\end{array}$ & $\begin{array}{l}\text { pPD5205-30 } \\
30,469 \\
\text { pPD5205.21, } \\
20,830\end{array}$ & $\begin{array}{l}\text { pPD885-27, } \\
27,106 \\
\text { pPD885-29, } \\
29,233\end{array}$ & $\begin{array}{l}\text { pNBC2815-21, } \\
21,045\end{array}$ \\
\hline No. scaffolds & 2 & 3 & 3 & 3 & 3 & 2 \\
\hline GC (\%) & 62.75 & 62.27 & 62.27 & 62.27 & 62.25 & 62.3 \\
\hline Genes (total) & 3,929 & 3,994 & 4,005 & 4,005 & 4,041 & 3,972 \\
\hline Genes (coding) & 3,129 & 3,215 & 3,238 & 3,236 & 3,292 & 3,207 \\
\hline Transfer RNAs & 54 & 52 & 52 & 52 & 52 & 52 \\
\hline Ribosomal RNAs & 6 & 6 & 6 & 6 & 6 & 6 \\
\hline Other RNAs & 245 & 86 & 86 & 86 & 86 & 87 \\
\hline CRISPR no. & 2 & 1 & 1 & 1 & 1 & 1 \\
\hline \multicolumn{7}{|c|}{ Carbohydrate-active enzyme functional classification and corresponding genes } \\
\hline $\begin{array}{l}\text { Carbohydrate-related } \\
\text { molecules }\end{array}$ & 23 & 20 & 20 & 20 & 20 & 22 \\
\hline Carbohydrate esterases & 4 & 4 & 4 & 4 & 4 & 4 \\
\hline Glycoside hydrolases & 82 & 76 & 76 & 76 & 76 & 78 \\
\hline Glycosyl transferases & 53 & 51 & 51 & 51 & 51 & 53 \\
\hline Polysaccharide lyases & 3 & 4 & 4 & 4 & 5 & 4 \\
\hline Auxiliary activities & 2 & 2 & 2 & 2 & 2 & 2 \\
\hline Total & 167 & 157 & 157 & 157 & 158 & 163 \\
\hline \multicolumn{7}{|c|}{ Secondary metabolites related synthetic genes } \\
\hline $\begin{array}{l}\text { Nonribosomal peptide } \\
\text { synthetases }\end{array}$ & 83 & 0 & 0 & 0 & 41 & 0 \\
\hline Siderophores & 9 & 0 & 0 & 0 & 0 & 0 \\
\hline Bacteriocins & 19 & 0 & 0 & 0 & 0 & 0 \\
\hline Arylpolyenes & 34 & 31 & 31 & 31 & 0 & 31 \\
\hline \multicolumn{7}{|l|}{ Type $\mathrm{N}$ secretion systems } \\
\hline T2SS & 10 & 10 & 10 & 10 & 10 & 10 \\
\hline T3SS & 159 & 160 & 161 & 161 & 156 & 157 \\
\hline T4SS & 7 & 5 & 5 & 5 & 9 & 6 \\
\hline
\end{tabular}

a This study.

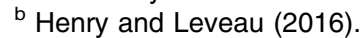

${ }^{\mathrm{c}}$ Gétaz et al. (2017).

Nanopore sequencing were constructed with an insert size of $10 \mathrm{~kb}$. For the Illumina sequence, an Illumina library with an insertion size of $350 \mathrm{bp}$ was built and was quantified using the Agilent 2100 Bioanalyzer (Agilent Technologies). Finally, the Nanopore assembly was polished using the Illumina reads to correct base errors.

After that, the genome assembly was performed using Unicycler software (Wick et al. 2017), using Illumina and Nanopore generation data. A total of $4.27 \mathrm{~Gb}$ of Nanopore short reads, representing 1,043x coverage of the YL19 genome, and $1.75 \mathrm{~Gb}$ of Illumina short reads $(428 \times)$ were generated (Table 1). The final genome size of YL19 was 4.11 Mb, which contains a $0.02 \mathrm{Mb}$ plasmid (Fig. 1). The strain PD 885, also known as LMG708, is the type $X$. fragariae strain, isolated in the United States by B. W. Kennedy in 1962 (Kennedy and King 1962). Strains NBC 2815 and PD 5202 were both isolated in the Netherlands from Fragaria $\times$ ananassa in 2011 and 2005, respectively (Gétaz et al. 2017). Strains FaP21and FaP29 are originated from the United States in 2011 (Henry and Leveau 2016). The size of YL19 genome and plasmid were smaller than PD885, NBC2815, PD5205, Fap21, and Fap29, but the GC content of YL19 was similar to PD885, NBC2815, PD5205, Fap21, and Fap29 (Table 1). Coding gene prediction for YL19 was used by GeneMarkS (version 4.17) (Besemer et al. 2001). The YL19 genome has a total of 3,929 genes, of which 3,129 are coding genes. Compared with PD885, NBC2815, PD5205, Fap21, and Fap29, YL19 lacked 109 coding genes (Table 1). Using Gene Ontology (Ashburner et al. 2000), Kyoto Encyclopedia of Genes and Genomes (Kanehisa et al. 2004), Cluster of Orthologous Groups of proteins 
(Galperin et al. 2015), and carbohydrate-active enzymes (CAZymes) (Cantarel et al. 2009) databases for gene function annotation. Compared with PD885, NBC2815, PD5205, Fap21, and Fap29, YL19 has more CAZyme genes, especially glycoside hydrolases (Table 1). antiSMASH (version 2.0.2) (Medema et al. 2011) was used for secondary metabolism gene clusters annotation. YL19 has more secondary metabolic genes than PD885, NBC2815, PD5205, Fap21, and Fap29, especially in the nonribosomal peptide synthetases, siderophore, and bacteriocins (Table 1). The protein sequence-function database and EffectiveT3 (version 1.0.1) (Eichinger et al. 2016) were used for the type $\mathrm{N}$ secretion system (TNSS) annotations and T3SS effector protein prediction, respectively. All the strains evaluated in the study have only three types of secretion systems, and there was no significant difference in the number of each secretion system between strains (Table 1).

The sequence of the $X$. fragariae YL19 genome can be employed in intraspecific and interspecies comparative genomic studies. In addition, this new genome ought to clarify the molecular mechanisms of genome evolution, host adaptation, and pathological process of $X$. fragariae.

\section{Data Availability}

The YL19 genome sequence data has been deposited at DDBJ/ENA/GenBank database under accession number CP071955. The sequenced strain is stored at Northwest A\&F University in China.

\section{Literature Cited}

Amil-Ruiz, F., Blanco-Portales, R., Muñoz-Blanco, J., and Caballero, J. L. 2011. The strawberry plant defense mechanism: A molecular review. Plant Cell Physiol. 52:1873-1903.

Ashburner, M., Ball, C. A., Blake, J. A., Botstein, D., Butler, H., Cherry, J. M., Davis, A. P., Dolinski, K., Dwight, S. S., Eppig, J. T., Harris, M. A., Hill, D. P., Issel-Tarver, L., Kasarskis, A., Lewis, S., Matese, J. C., Richardson, J. E., Ringwald, M., Rubin, G. M., and Sherlock, G. 2000. Gene ontology: Tool for the unification of biology. Nat. Genet. 25:25-29.

Besemer, J., Lomsadze, A., and Borodovsky, M. 2001. GeneMarkS: A selftraining method for prediction of gene starts in microbial genomes. Implications for finding sequence motifs in regulatory regions. Nucleic Acids Res. 29:2607-2618.

Cantarel, B. L., Coutinho, P. M., Rancurel, C., Bernard, T., Lombard, V., and Henrissat, B. 2009. The Carbohydrate-Active EnZymes database (CAZy): An expert resource for Glycogenomics. Nucleic Acids Res. 37 (Database): D233-D238.

Eichinger, V., Nussbaumer, T., Platzer, A., Jehl, M. A., Arnold, R., and Rattei, T. 2016. EffectiveDB-Updates and novel features for a better annotation of bacterial secreted proteins and Type III, IV, VI secretion systems. Nucleic Acids Res. 44 (D1):D669-D674.

Galperin, M. Y., Makarova, K. S., Wolf, Y. I., and Koonin, E. V. 2015. Expanded microbial genome coverage and improved protein family annotation in the COG database. Nucleic Acids Res. 43 (D1):D261-D269.

Gétaz, M., van der Wolf, J. M., Blom, J., and Pothier, J. F. 2017. Complete genome sequences of three isolates of Xanthomonas fragariae, the bacterium responsible for angular leaf spots on strawberry plants. Genome Announc. 5:00642-17.

Henry, P. M., and Leveau, J. H. 2016. Finished genome sequences of Xanthomonas fragariae, the cause of bacterial angular leaf spot of strawberry. Genome Announc. 4:01271-16.
Kanehisa, M., Goto, S., Kawashima, S., Okuno, Y., and Hattori, M. 2004. The KEGG resource for deciphering the genome. Nucleic Acids Res. 32:D277-D280.

Kennedy, B. W., and King, T. H. 1962. Angular leafspot of Strawberry caused by Xanthomonas fragariae sp. nov. Phytopathology 52:873-875.

Kim, M. S., Jin, J. S., Kwak, Y. S., and Hwang, G. S. 2016. Metabolic response of strawberry (Fragaria $\times$ ananassa) leaves exposed to the angular leaf spot bacterium (Xanthomonas fragariae). J. Agric. Food Chem. 64:1889-1898.

Li, Y. L., Wang, D. J., Ma, Y. Y., Cai, X. L., Xiao, S. Y., Wen, Y. Q., and Feng, J. Y. 2021. First Report of Xanthomonas fragariae strain YL19 causing crown infection pockets in strawberry in Liaoning Province, China. Plant Dis. 105:2237.

Medema, M. H., Blin, K., Cimermancic, P., de Jager, V., Zakrzewski, P., Fischbach, M. A., Weber, T., Takano, E., and Breitling, R. 2011. antiSMASH: Rapid identification, annotation and analysis of secondary metabolite biosynthesis gene clusters in bacterial and fungal genome sequences. Nucleic Acids Res. 39 (suppl_2): W339-W346.

Moslem, M. A., Bahkali, A. H., Abd-Elsalam, K. A., and Wit, P. J. 2010. An efficient method for DNA extraction from Cladosporioid fungi. Genet. Mol. Res. 9:2283-2291.

Roberts, P. D., Berger, R. D., Jones, J. B., Chandler, C. K., and Stall, R. E. 1997. Disease progress, yield loss, and control of Xanthomonas fragariae on strawberry plants. Plant Dis. 81:917-921.

Song, Z., Yang, C., Zeng, R., Gao, S. G., Cheng, W., Gao, P., Xu, L., and Dai, F. 2021. First report of strawberry crown rot caused by Xanthomonas fragariae in China. Plant Dis. 105:2711.

Vandroemme, J., Cottyn, B., Baeyen, S., De Vos, P., and Maes, M. 2013. Draft genome sequence of Xanthomonas fragariae reveals reductive evolution and distinct virulence-related gene content. BMC Genomics 14:829.

Wick, R. R., Judd, L. M., Gorrie, C. L., and Holt, K. E. 2017. Unicycler: Resolving bacterial genome assemblies from short and long sequencing reads. PLOS Comput. Biol. 13:e1005595. 